\title{
Analysis of differentially expressed genes in hyperthyroid-induced hypertrophied heart by cDNA microarray
}

\author{
K De, G Ghosh, M Datta, A Konar, J Bandyopadhyay, \\ D Bandyopadhyay, S Bhattacharya and A Bandyopadhyay \\ Indian Institute of Chemical Biology, 4 Raja S. C. Mullick Road, Kolkata 700032, India \\ ${ }^{1}$ West Bengal University of Technology, BF-14, Salt Lake, Kolkata 700064, India \\ (Requests for offprints should be addressed to A Bandyopadhyay)
}

\begin{abstract}
Experiments were carried out to identify the altered genes in hyperthyroid rat heart and their influence on the functions of cardiac myocytes. Chronic treatment of rats with 3,5,3' triiodo-L-thyronine (T3) resulted in a prominent increase in the size of the left ventricle with increased wall thickness and reduced chamber volume leading to concentric cardiac hypertrophy. The heart weight to body weight ratio $(\mathrm{HW} / \mathrm{BW})$ in hyperthyroid rats was increased by about $58 \%$ over that of normal rats. Using cDNA microarray comprising 588 genes, we compared the differences in mRNA expression of hyperthyroid and normal rat heart. Based on a threshold of greater than 10\% change, about 37 genes were found to be regulated by T3. Further analyses by Western blotting, Northern blotting and real-time quantitative RT-PCR of some of the genes confirmed the microarray results. The T3-altered genes encode various types of proteins related to metabolism, matrix and cytoskeletal structures, growth factors, tran-
\end{abstract}

scription factors, $\mathrm{Ca}^{2+}$-channels etc. The physiological significance of one of these altered proteins in hyperthyroid heart, insulin-responsive glucose transporter (GLUT) type 4 (GLUT4), was studied in detail. The expression of GLUT4 was drastically reduced in the ventricular tissues of hyperthyroid heart. Insulin-induced glucose uptake in hyperthyroid cardiomyocytes was reduced significantly, indicating the impaired glucose transport in cardiac cells. Interestingly, a few genes such as GLUT4, cytochrome P450 isoforms, superoxide dismutase (SOD), collagens, matrix metalloproteinases (MMP), tissue inhibitors of matrix metalloproteinases etc. which had not been reported earlier were found to be altered in hyperthyroid heart. Our results show some new aspects of hyperthyroid heart which will be important in assessing the pathophysiology of hypertrophied cardiomyocytes.

Journal of Endocrinology (2004) 182, 303-314

\section{Introduction}

Thyroid hormones have profound effects on metabolism, growth and development (Oppenheimer et al. 1987). Although the action of thyroid hormone involves virtually all organ systems, the heart responds to minimal changes in the serum thyroid hormone levels. It was reported that defects in thyroid hormone receptor expression and thyroid hormone signaling occur in the heart of failing/ hypertrophied human patients (Kinugawa et al. 2001). Moreover hyperthyroid human patients experience cardiovascular complications with alteration of several cardiac parameters. These include increased resting heart rate, abnormal myocardial contractility and an increased left ventricular muscle mass (Fadel et al. 2000). Therefore, prolonged hyperthyroidism, if left untreated, results in abnormal myocardial function and cardiac hypertrophy that may lead to heart failure (Chien et al. 1993, Cohn 1996).
Cardiac hypertrophy is an adaptive enlargement of the myocardium characterized by increased size of individual myocytes in response to a wide variety of extrinsic as well as intrinsic stimuli. Extrinsic stimuli are pressure overload, volume overload and neurohumoral factors. Intrinsic stimuli include contractile abnormalities due to altered expression or mutations of the sarcomeric proteins. Although hypertrophic growth is initially compensatory in nature, the function in the hypertrophied heart eventually becomes abnormal and a transition from hypertrophy to heart failure occurs (Feldman et al. 1993). Due to abnormal heart function in the long run, the overall growth process initiating the cardiac disease has been termed as pathological hypertrophy (Scheuer \& Battrick 1987).

Treatment of cardiac myocyte by 3,5,3' triiodo-Lthyronine (T3) causes beta adrenergic stimulation, increased protein kinase A (PKA) activity, cAMP production and phosphorylation of proteins related to $\mathrm{Ca}^{2+}$ 
cycling kinetics (Kiss et. al. 1994, Ojamaa et al. 2000). Thus, beta-adrenoreceptor stimulation may be responsible for thyroid-mediated positive inotropic actions and enhanced atrial contractility (Dillman 1990). Because thyroid hormone also enhances cardiac functions characterized by faster myocardial relaxation and a decline in the cytosolic $\mathrm{Ca}^{2+}$ transient (MacKinnon et al. 1988, Bing et al. 1994, Kiss et al. 1994), thyroid hormone treatment has been suggested for improving cardiac performance in the postinfarction model of heart failure (Gay et al. 1988, Pennock et al. 1993, Mahaffey et al. 1995). However, the long-term effects of thyroid hormone on cardiac function and metabolism are incompletely known. Recently, it has been shown that thyroid hormone-induced cardiac hypertrophy is associated with an initial increase in cardiac performance followed by a decline in cardiac function indicating the detrimental effects of chronic hyperthyroidism (Degens et al. 2003).

Although it is reported that thyroid hormone influences cardiac growth and metabolism via the signaling pathway distinct from other hypertrophic stimuli, the molecular mechanisms underlying hyperthyroid-induced versus pathological hypertrophy remain uncertain (Scheuer et al. 1982, Schaible et al. 1984, Izumo et al. 1987). Some of the unique features of thyroid hormone-induced gene expression in cardiac muscle are induction of alpha myosin heavy chain (MHC- $\alpha$ ), sarco-endoplasmic reticulum $\mathrm{Ca}^{2+}$ ATPase (SERCA) and repression of beta MHC (MHC- $\beta$ ) (Dillmann 1990, Kinugawa et al. 2001, Klein \& Ojamaa 2001). It is also postulated that thyroid hormoneinduced improvement in myocardial contractility is partly due to the differential MHC gene expression (Fadel et al. 2000). To understand the gene expression programme in thyroid hormone-induced hypertrophied heart, we have conducted cDNA microarray analysis of heart tissue obtained from rats treated/untreated with T3 for 15 days. In the present study, alterations of at least 37 genes involved in cardiovascular function are demonstrated and the physiological significance of one of these altered genes has been explored in detail. Microarray analysis revealed that a few genes involved in the pathological hypertrophy are also altered in hyperthyroid heart in addition to the genes that are not yet known to be thyroid hormone responsive in cardiac tissues. Accordingly, we demonstrated that prolonged treatment of rats with $\mathrm{T} 3$ results in abnormal glucose transport into cardiomyocytes, which could be one of the important detrimental effects of long-term thyroid hormone treatment.

\section{Materials and Methods}

\section{Animals}

Sprague-Dawley rats were obtained from the Institute's animal facility. The animals were handled as per the guidelines of the animal ethics committee of this Institute.

\section{Treatment of rats with T3}

Sprague-Dawley rats were intraperitoneally injected daily with 7.5 $\mu \mathrm{g}$ T3/100 g body weight (Hamasaki et al. 2000, Weitzel et al. 2001) for 15 days. The control group was treated with the same volume of saline. The animals were killed on the 16th day. In parallel groups, rats treated with $\mathrm{T} 3$ for 15 days were maintained untreated for another 15 days to study the effect of $\mathrm{T} 3$ withdrawal, i.e. these rats were killed 1 month after the start of the experiment. Animals were anesthetized and hearts were surgically removed and immersed in ice-cold $0.9 \% \mathrm{NaCl}$. The degree of hypertrophy was calculated in terms of heart weight:body weight ratio.

\section{Estimation of serum T3 concentration}

To ensure the development of the hyperthyroid condition the level of T3 in the serum was detected by radioimmunoassay using the $\mathrm{T} 3$ radioimmunoassay kit (Bhaba Atomic Research Center, India) as per the manufacturer's protocol.

\section{Histology}

Cardiac tissue from control, T3-treated or T3-withdrawn rats was fixed in 10\% formalin and embedded in paraffin following routine procedures. Tissue sections of $5 \mu \mathrm{m}$ thickness were prepared and stained with Mayer's hematoxylin and eosin. The sections were mounted and observed under microscope at $\times 400$ magnification.

\section{Northern blot analysis}

Total left ventricular RNA from control and T3-treated rats was isolated using TriReagent (Sigma-Aldrich). About $15 \mu \mathrm{g}$ RNA was resolved on 1\% agarose/formaldehyde gels and transferred to nylon membrane (Millipore). After transfer, RNA was fixed by u.v. cross linking, hybridized with $\left[\alpha-{ }^{32} \mathrm{P}\right] \mathrm{dATP}$ labeled (Hexalabel Plus DNA labeling kit, MBI Fermentas), atrial natriuretic factor (ANF) cDNA and GLUT4 cDNA (a gift from Dr Jeffry E Pessin, University of Iowa, Iowa). The membranes were washed twice for $10 \mathrm{~min}$ each with $2 \times \mathrm{SSC}, 0 \cdot 1 \%$ SDS at room temperature followed by a single wash with the same solution at $65{ }^{\circ} \mathrm{C}$ for $30 \mathrm{~min}$. Membranes were exposed to Kodak autoradiographic film.

\section{cDNA expression arrays}

An Atlas cardiovascular array kit was purchased from Clontech (USA). These arrays consisted of 588 cDNAs (organized into broad functional groups), nine housekeeping control cDNAs and negative controls. Membrane hybridization was performed according to the manufacturer's protocol. Briefly, $5 \mu \mathrm{g}$ total RNA from the left 
ventricular tissues of control and T3-treated rat hearts were reverse transcribed in the presence of $\left[\alpha_{-}{ }^{32} \mathrm{P}\right] \mathrm{dATP}$ (3000Ci/mmole; Amersham Pharmacia) using MMLV reverse transcriptase (100 units) and CDS primer mix at $50{ }^{\circ} \mathrm{C}$ for $25 \mathrm{~min}$. Array membranes were hybridized overnight at $68^{\circ} \mathrm{C}$ in Express Hybridization solution containing $100 \mu \mathrm{g} / \mathrm{ml}$ sheared salmon testes DNA. The array membranes were then washed twice with $2 \times$ SSC, $0 \cdot 1 \%$ SDS at room temperature followed by a single wash with the same solution at $65{ }^{\circ} \mathrm{C}$ for $30 \mathrm{~min}$. The array membranes were exposed to Kodak (X-OMAT, Sigma) autoradiographic film for $48 \mathrm{~h}$. Spots that developed were normalized by equalizing the intensity of signals from a set of housekeeping genes provided on the array. The autoradiographs were scanned and analyzed using ImageJ software (National Institute of Health, Bethesda, MD, USA). The results presented are the means \pm S.E.M. of three separate microarray experiments using RNA prepared from hearts from three different batches of treatments.

\section{Western blot analysis}

For Western blot analysis, either whole homogenate $(80 \mu \mathrm{g}$ protein sample) or microsome preparations $(50 \mu \mathrm{g}$ proteins sample) were used. The whole homogenate from the left ventricular tissues was prepared as described earlier (Bandyopadhyay et al. 2000). Briefly, rat heart tissue was homogenized in a buffer containing $2 \mathrm{mM}$ Tris- $\mathrm{HCl}(\mathrm{pH}$ $7 \cdot 8$ ), $150 \mathrm{mM} \mathrm{NaCl}, 1 \mathrm{mM}$ phenylmethylsulfonyl fluoride (PMSF) and $100 \mathrm{mg} / \mathrm{ml}$ pepstatin A. For the microsome preparation, the whole homogenate was centrifuged at $4000 \mathrm{~g}$ for $15 \mathrm{~min}$ at $4{ }^{\circ} \mathrm{C}$. The post-nuclear supernatants were subjected to a centrifugation for $40 \mathrm{~min}$ at $20000 \mathrm{~g}$ at $4{ }^{\circ} \mathrm{C}$ using a fixed-angle Beckman T50 rotor. The supernatants were then ultra-centrifuged at $105000 \mathrm{~g}$ for $90 \mathrm{~min}\left(4{ }^{\circ} \mathrm{C}\right)$. The pellet was resuspended in the homogenizing buffer and the expression of GLUT1 and GLUT4 was examined in this preparation. Immunoblot analyses with the antibodies against SOD-1, GLUT1, GLUT4, COX1 (cyclo-oxygenase 1), collagen IV, MMP2, $\mathrm{Na}-\mathrm{Ca}-$ exchanger and MHC- $\beta$ were performed as described earlier (Bandyopadhyay et al. 2000). Anti-goat SOD-1, anti-rabbit GLUT1, anti-goat GLUT4, antirabbit COX1, anti-rabbit collagen IV antibodies were purchased from Santa Cruz Biotech (Santa Cruz, CA, USA). Anti-mouse $\mathrm{Na}-\mathrm{Ca}$-exchanger and anti-rabbit MMP2 antibodies were purchased from Sigma. Antibody against MHC- $\beta$ was a gift from Dr Do Han Kim (Gwangju Institute of Science and Technology, Gwangju, South Korea). Immunoblotting in parallel sets was performed with anti-mouse $\beta$-actin antibody (Sigma) as loading controls both with whole homogenate and microsome preparations separately. For quantification, the pixel intensities of the respective bands of the immunoblots from three different individual rats were calculated using ImageJ software (NIH). The intensities of the bands are expressed as relative pixel density (arbitrary units).

\section{SOD activity}

Cardiac tissues $(200 \mathrm{mg})$ were homogenized in $0.5 \mathrm{ml}$ of $0.05 \mathrm{M}$ potassium phosphate buffer containing $0.1 \mathrm{mM}$ EDTA (pH 7.8). The enzyme was extracted with $0.35 \mathrm{ml}$ chloroform:ethanol (3:5). After centrifugation for $5 \mathrm{~min}$ at $12000 \mathrm{~g}$, the supernatant was carefully collected and used for the $\mathrm{Cu}, \mathrm{Zn}-\mathrm{SOD}$ assay (Martin et al. 1987). The SOD activity is expressed as units/mg protein.

\section{Real-time quantitative RT-PCR analysis}

One-step quantitative RT-PCR of each sample was performed in triplicate using the QuantiTect SYBR Green RT-PCR kit (Qiagen) and the iCycler realtime detection system and software (Bio-Rad) according to the manufacturers' instructions. Sequence-specific PCR primers were designed using the GeneFisher software (http:// bibiserv.techfak.uni-bielefeld.de/genefisher/) based on published nucleotide sequences. A standard curve for each cDNA was obtained by performing amplifications from serial dilutions of myocardial total RNA. For all specific mRNA amplified, linear inverse correlations were observed between an amount of RNA and the $C_{\mathrm{T}}$ values (number of cycles needed to generate a fluorescent signal above a pre-defined threshold). A higher $C_{\mathrm{T}}$ value indicates a lower amount of mRNA in the sample and vice versa. Expression level of the 'housekeeping gene' GAPDH was used to normalize for variations in the amount of RNA, purity etc. The normalized $C_{\mathrm{T}}$ values of T3-treated samples for each cDNA were expressed as percentage change compared with the untreated control; they are depicted as histograms in Fig. 4.

\section{Isolation of adult rat ventricular cardiomyocytes}

Adult rat ventricular cardiomyocytes from control and T3-treated animals were isolated as described previously (Piper et al. 1982) with some modifications. The left ventricles were cut, minced thoroughly and the tissue was incubated at $37^{\circ} \mathrm{C}$ in enzyme solution $(0 \cdot 1 \%$ collagenase and $0.1 \%$ hyaluronidase in calcium-free Krebs-Henseleit (KH) bicarbonate buffer $(\mathrm{NaCl} 119 \mathrm{mM}, \mathrm{KCl} 4.7 \mathrm{mM}$, $\mathrm{CaCl}_{2} 1.25 \mathrm{mM}, \mathrm{MgSO}_{4} 1.2 \mathrm{mM}, \mathrm{NaHCO}_{3} 25 \mathrm{mM}$, $\mathrm{KH}_{2} \mathrm{PO}_{4} 1.2 \mathrm{mM}$, Hepes $12.5 \mathrm{mM}$, BSA 0.2\%, pH 7.4) for $30 \mathrm{~min}$ in a $\mathrm{CO}_{2}$ incubator with intermittent shaking. After digestion the cell suspension was centrifuged at $50 \mathrm{~g}$ for $1 \mathrm{~min}$. The pellet obtained was suspended in wash medium (3 parts of KH buffer +1 part of medium $199+$ $10 \% \mathrm{FBS}$ ) and centrifuged at $50 \mathrm{~g}$ for $1 \mathrm{~min}$. The pellet contained 90-97\% rod-shaped viable ventricular myocytes which were resuspended in glucose-free $\mathrm{KH}$ buffer. The 
cells were stored in the $\mathrm{CO}_{2}$ incubator at $37^{\circ} \mathrm{C}$ for $30 \mathrm{~min}$ before they were used for monitoring glucose uptake.

\section{Glucose uptake}

Glucose uptake was monitored following the protocol described earlier (Roy et al. 2003) with some modifications. Ventricular cardiomyocytes were incubated for 30 min either in the absence (basal) or presence of porcine insulin $(100 \mathrm{nM})$. After $30 \mathrm{~min}$ of insulin treatment, 2-deoxy-D- $\left[{ }^{3} \mathrm{H}\right]$ glucose $(0 \cdot 4 \mathrm{nmol})$ was added to each incubation and, after $5 \mathrm{~min}$, uptake was terminated by washing cells three times with ice-cold $\mathrm{KH}$ buffer in the presence of $0.3 \mathrm{mM}$ Phloretin to correct the glucose uptake data for simple diffusion and non-specific trapping of radioactivity. Cells were pelleted down, washed twice with $\mathrm{KH}$ buffer and sonicated in presence of Nonidet P40 (NP40) and acetone. $\left[{ }^{3} \mathrm{H}\right]$ deoxy glucose was measured in a liquid scintillation counter (Packard, Tricarb 2100TR) and the results are expressed as c.p.m. per mg protein.

\section{Statistical analysis}

Data are presented as means \pm S.E.M. The level of significance was calculated using ANOVA. $P \leq 0.05$ was considered to be significant.

\section{Results}

Development of left ventricular hypertrophy in hyperthyroid rats

Figure $1 \mathrm{~A}$ shows a clear increase in size of the left ventricle in T3-treated rats (T3, 4.04 $\pm 0.04 \mathrm{ng} / \mathrm{ml}$ serum) compared with the vehicle-treated animals (T3, 1.4 $\pm 0.02 \mathrm{ng} / \mathrm{ml}$ serum) that was further evident from the longitudinal sections of hearts. The histological sections of the left ventricular tissues displayed a normal, healthy and compact arrangement of myofibrils in control hearts whereas a massive enlargement of individual myofibrils and myocyte disarray occurred in the hypertrophied heart; normal architecture was restored in the heart following T3 withdrawal (Fig. 1A).

To assess the development of cardiac hypertrophy, combined left/right ventricle:body weight $(\mathrm{HW} / \mathrm{BW})$ ratios were measured. Figure $1 \mathrm{~B}$ shows that $\mathrm{HW} / \mathrm{BW}$ ratio increased with the duration of thyroid hormone treatment; the ratio reached a maximum value, and exhibited a $58 \%$ increase $(P<0 \cdot 001)$ over that of control rat group, after 15 days. When T3 injections were discontinued for 15 days following 15 days of daily treatment, there was a restoration of $\mathrm{HW} / \mathrm{BW}$ ratio $(3 \cdot 0 \pm 0 \cdot 09)$ similar to that of control rats $(2 \cdot 88 \pm 0 \cdot 04)$ indicating the specificity of thyroid hormone action on heart in the present study (Fig. 1B).
Thyroid hormone induced ANF expression in left ventricular tissues

Induction of ANF synthesis in ventricular tissue is a common event in various forms of cardiac hypertrophy (Chien et al. 1993). As shown in Fig. 2, the ANF mRNA level was very high in the left ventricular tissue of T3-treated rat heart compared with saline-treated control. When the T3 treatment was discontinued after the 15th day, ANF level was reduced. These data indicated that a prolonged hyperthyroid condition also induces severe cardiomyopathy.

\section{Gene profile in hyperthyroid rat heart}

To examine the effect of thyroid hormone treatment on cardiac gene expression, RNA from normal and T3treated rat hearts was prepared, reverse transcribed and radiolabeled with $\left[\alpha_{-}{ }^{32} \mathrm{P}\right] \mathrm{dATP}$; the labeled probes thus prepared were used for hybridization of the array membranes separately as described in Materials and Methods. The autoradiographs were scanned and analyzed using ImageJ software (NIH). After normalization of the signals with the control, 37 genes were found to be altered in T3-treated heart (Table 1). Out of these, 11 genes were upregulated and 26 genes were downregulated in the heart due to T3 treatment. The altered genes can be grouped into five categories based on their functions. These are related to general metabolism, cytoskeletal/matrix protein, hormone/growth factor, $\mathrm{Ca}^{2+}$-channel proteins and the proteins related to receptor transcription. A difference of above $10 \%$ in the intensity of the spots in the microarray blots was validated by Western blot analysis (Fig. 3). Hence a difference of above $10 \%$ is considered to be the real signal and is included in the altered gene list. About $212 \%$ increase in the expression of ANF in the T3-treated heart was observed which is consistent with typical hypertrophic growth of cardiomyocytes (Chien et al. 1993). A plethora of metabolic enzyme genes of the cytochrome P450 system were upregulated in T3-treated heart. MHC- $\alpha$ was upregulated and the MHC- $\beta$ was downregulated in hyperthyroid rat heart as reported earlier (Dillmann 1990, Fadel et al. 2000, Kinugawa et al. 2001, Klein \& Ojamaa 2001). Some of the genes important for cardiovascular functions which are downregulated but not yet known to be influenced by thyroid hormone are $\mathrm{Cu}, \mathrm{Zn}-\mathrm{SOD}$, GLUT4, tissue inhibitor of metalloproteinase 2 (TIMP2), collagen XVI $\alpha 1$, collagen IV $\alpha 4$, vascular endothelial growth factor receptor and estrogen-related receptor alpha $(E R R \alpha)$. Similarly, the fact that MMP2, retinoic acid receptor alpha $(\operatorname{RAR} \alpha)$ and $\operatorname{RAR} \gamma$ are positively regulated by thyroid hormone in the heart is revealed for the first time.

\section{Validation of microarray results}

Some of the genes altered in hyperthyroid rat heart, as revealed by the cDNA microarray analysis (Table 1), were 
A

C

$\mathbf{T}$

W

a
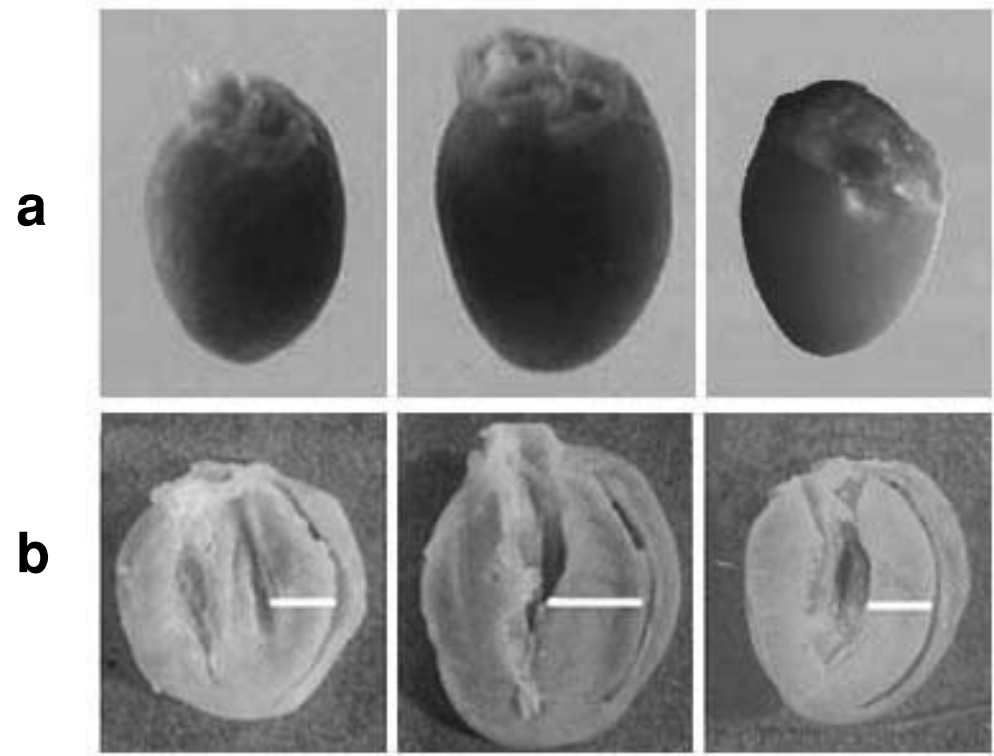

C
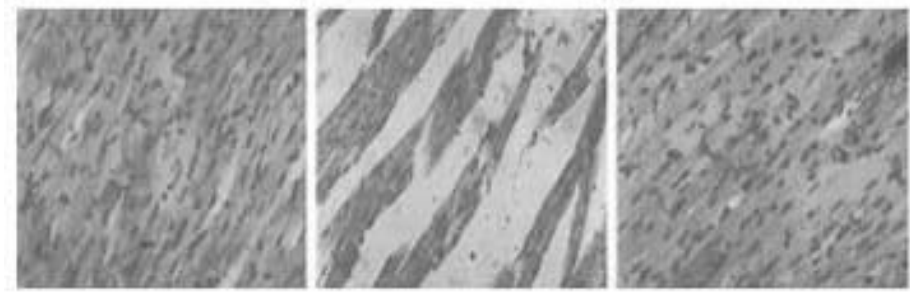

B

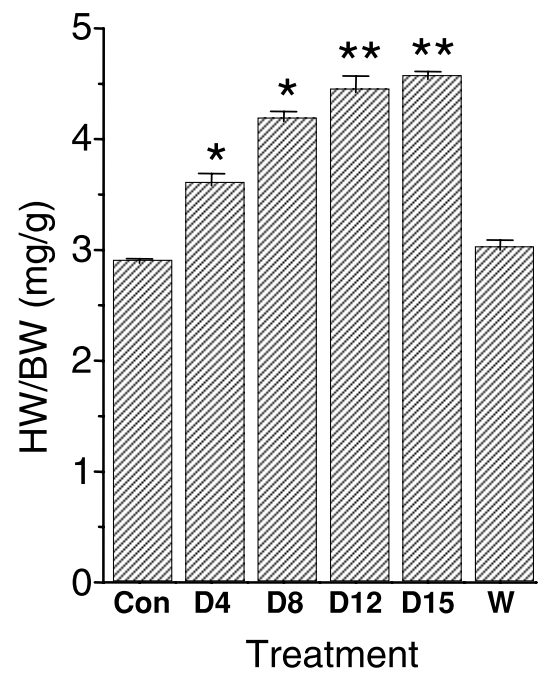

Figure 1 Assessment of left ventricular hypertrophy in hyperthyroid rat.

(A) Morphology, a; longitudinal section, b; and histological examination, c ( $\times 400$ magnification) of hearts from rats injected with vehicle (C) or T3 $(7.5 \mu \mathrm{g} / 100 \mathrm{~g}$ body weight) for 15 days (T) or 15 days withdrawal after T3 administration (W) showing the increased wall thickness (thick line) and reduced chamber volume in hyperthyroid rat heart. (B) Heart weight:body weight ratio $(\mathrm{mg} / \mathrm{g})$ of rats treated without T3 (Con) or with T3 for 4 days (D4), 8 days (D8), 12 days (D12) or 15 days (D15) or 15 days withdrawal following T3 treatment $(\mathrm{W})$. The data represent means \pm S.E.M. of 12 individual animals. ${ }^{*} P<0 \cdot 01$ vs control; ${ }^{*} P<0 \cdot 001$ vs control. 


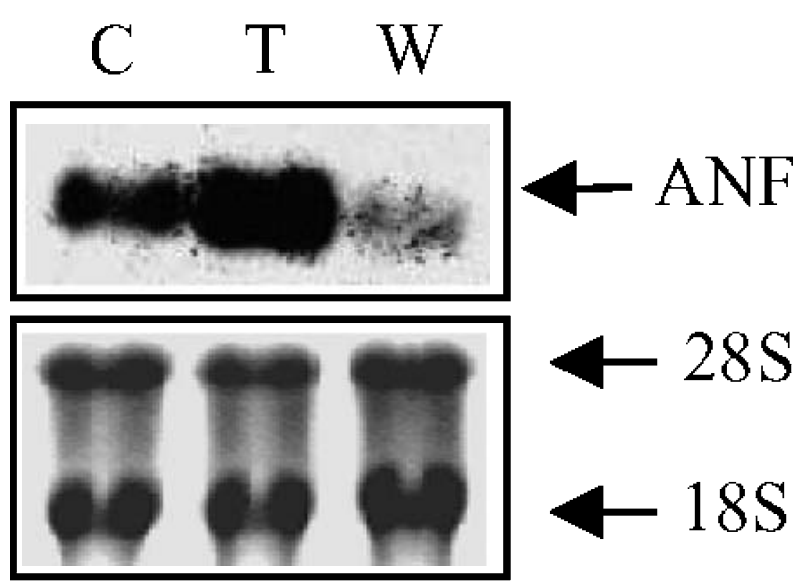

Figure 2 Thyroid hormone induced ANF expression in rat heart. Ventricular tissues from vehicle (C), T3-treated for 15 days (T) or T3-treated for 15 days followed by 15 days without any treatment (W) were used to extract total RNA which was transferred to nylon membrane and subjected to Northern blot analysis with rat ANF cDNA as a probe. The lower panel shows the loading control of total RNA in three lanes.

further examined by Western blot analysis using homogenate prepared from the left ventricular tissues of control and hyperthyroid rat heart. Figure $3 \mathrm{~A}$ shows significantly increased $(P<0 \cdot 05)$ level of expression of MMP2 and COX1, and a decreased $(P<0 \cdot 05)$ level of expression of GLUT4, SOD, MHC- $\beta$, collagen IV $\alpha 4, \mathrm{Na}-\mathrm{Ca}^{2+}$ exchanger consistent with the cDNA microarray analysis. Since SOD expression was reduced, we additionally examined the activity of this antioxidant enzyme in the homogenate prepared from control and T3-treated rat hearts. It is interesting that SOD activity was also reduced significantly $(P<0 \cdot 01)$ in hypertrophied heart tissues (Fig. 3B).

Alteration of some of the nuclear hormone receptors was validated by real-time quantitative PCR. The real-time quantitative PCR analysis revealed that the expression of ERR $\alpha$ and mineralocorticoid receptor (MR) was reduced while that of $\operatorname{RAR} \alpha$ was increased in hyperthyroid rat heart compared with the control, consistent with microarray analysis (Fig. 4).

\section{Thyroid hormone inhibits GLUT4 expression in heart}

The inhibition of GLUT4 expression as evident from microarray analysis prompted us to investigate the expression of GLUT4 with the progression of cardiac hypertrophy following T3 treatment. Microsomes were prepared from left ventricular tissues after treatment of rats without or with T3 for 4 and 15 days and were subjected to Western blot analysis. As shown in Fig. 5, the expression of GLUT4 was reduced after 4 days and was further reduced after 15 days of $\mathrm{T} 3$ treatment. The level of GLUT4 was restored to normal when T3 treatment was discontinued for 15 days after 15 days of injection. These data indicate that hyperthyroidism repressed GLUT4 transcription in the heart.

\section{Thyroid hormone inhibits glucose uptake in cardiac myocytes}

To examine the effect of low levels of GLUT4 expression on the heart, glucose uptake in cardiomyocytes prepared from normal and T3-treated animals was examined. Cardiomyocytes from the adult rats were prepared and 2-deoxy-D- $\left[{ }^{3} \mathrm{H}\right]$ glucose uptake was monitored in the absence or presence of insulin. Figure $6 \mathrm{~A}$ shows that insulin-stimulated 2-deoxy-D- $\left[{ }^{3} \mathrm{H}\right]$ glucose uptake was reduced in the cardiomyocytes prepared from $\mathrm{T} 3$-treated rat, indicating the impairment of glucose transport in the hyperthyroid heart. Since the basal level of 2-deoxy-D$\left[{ }^{3} \mathrm{H}\right]$ glucose uptake was also reduced in cardiomyocytes of hyperthyroid rat, the level of GLUT1 in ventricular microsome preparations was examined by Western blot analysis with anti-GLUT1 antibody. As shown in Fig. 6B, the level of GLUT1 was also significantly reduced $(P<0.05)$ in $\mathrm{T} 3$-treated rat heart compared with the control.

\section{Discussion}

The key points of this study are: (1) thyroid hormone induces changes in gene expression in the heart, some of which were previously not known to be thyroid hormone responsive and associated with cardiac hypertrophy in vivo; (2) one of the consequences of long-term thyroid hormone treatment is a reduction of GLUT1 and GLUT4 expression and inhibition of glucose entry into the cardiac myocytes. Analysis of gene expression reveals that thyroid hormone signals the hypertrophic growth of the cardiac myocytes through a gene expression program distinct from other types of hypertrophic stimuli and altered genes are associated with the pathological hypertrophy. Whether the altered genes are directly regulated by T3 needs further study. Considering the characteristics of altered genes and specifically abnormal glucose handling of the cardiomyocytes, it is reasonable to suggest that in the event of increased excitation-contraction coupling, the hyperthyroid heart could fail due to defects in the energy metabolism.

Upon binding with thyroid hormone receptors localized in the DNA, thyroid hormone regulates expression of a wide variety of genes. Using cDNA microarray analysis, it has been shown recently that thyroid hormone regulates the expression of about 55 genes in its main target organ, the liver (Feng et al. 2000). Microarray analysis also demonstrated a thyroid hormone-induced gene profile in hypothyroid animals (Weitzel et al. 2003). Consistent with hyperthyroid-induced cardiovascular complications such as increased resting heart rate, myocardial contractility and 
Table 1 Gene profile in hyperthyroid heart

\section{Gene/protein name}

\section{Group}

Metabolism

Cytoskeletal/matrix proteins

Hormone/growth factor

$\mathrm{Ca}^{2+}$ channel protein

Receptor/transcription factors

Functionally unclassified protein
Cytochrome P450 IIB6, Cytochrome P450 2B3

Cytochrome P450 VIIIA1

Cytochrome P450 III A3

HDL-binding protein

Adipocyte fatty acid binding protein

Phospholipid transporter protein

Cyclo-oxygenase 1 (COX1)

Insulin responsive glucose transporter (GLUT) type 4 (GLUT4)

$\mathrm{Cu}, \mathrm{Zn}-\mathrm{SOD}$

Cardiac muscle myosin heavy chain $\alpha$ isoform (MHC- $\alpha$ )

Cardiac muscle myosin heavy chain $\beta$ isoform (MHC- $\beta$

Matrix metalloproteinase 2 (MMP2)

Tissue inhibitor of metalloproteinase 2 (TIMP2)

Collagen IV $\alpha 1$

Collagen XVI $\alpha 1$

L-selectin

Junction placoglobulin

Desmoplakin III

Erythrocyte adducin alpha subunit

Atrial natriuretic factor (ANF)

Placental growth factor 1

$\mathrm{Na}^{+}-\mathrm{Ca}^{2+}$ exchanger

Cardiac phospholamban

Estrogen-related receptor alpha $(E R R \alpha)$

Retinoic acid receptor alpha (RAR $\alpha)$

Retinoic acid receptor gamma (RAR $\gamma$ )

V-erb-related protein 3, transcription factor COUP2;

nuclear receptor subfamily 2 group $\mathrm{F}$ member 2 (NR2F2)

Progesterone receptor

Mineralocorticoid receptor

Purinoreceptor

Vascular endothelial growth factor receptor

Vasopressin V-3 receptor

Sterol regulatory element-binding transcription factor 1

Protein tyrosine phosphatase receptor type-F
GenBank

accession no.

M29874; J02864

D38145

M13785

M83789

J02874

L26232

M59979

M20747

J02947

D00943

M58018

J03210

J05593

M11315

M92642

M25280

M23410

Z68228

X58141

HS75640

X54936

M91368

M63603

X51416

X06614

M24857

X12795; X16155;

X58241

M15716

M16801

U41070

AF016050

D31833

U00968

Y00815

X69398

$\times 92762$
Induction/ repression

$+92 \cdot 3$

$+33 \cdot 49$

$+194.6$

$+120$

$-35.5$

$-56$

$+16.44$

$-24$

$-40 \cdot 4$

$+24$

$-30 \cdot 41$

$+15$

$-60 \cdot 86$

$-12$

$-56 \cdot 28$

$+18$

$-42 \cdot 55$

$-21 \cdot 4$

$+211$

$-30$

$-15$

$-77$

$-45.58$

$+26$

$+13.74$

$-41.63$

$-26$

$-45 \cdot 6$

$-41 \cdot 5$

$-43 \cdot 71$

$-23$

$-18 \cdot 3$

$+29 \cdot 16$

$-26 \cdot 1$ reduced following withdrawal of T3 treatment after 2 weeks (Table 1, Fig. 2). However, the reason for the greater reduction in ANF level in the ventricular tissues after T3 withdrawal, compared to the control, is unclear. It is likely that some of the molecular phenotypes in the hearts of the withdrawal group may not be identical to the control hearts although the hypertrophy is completely regressed. This could be an interesting mechanism, which needs further detailed study.

Cytochrome P450 enzymes catalyze oxidation of a wide range of drugs and other xenobiotics, and are responsible for the metabolism of endogenous compounds. Expression of cytochrome P450 mono-oxygenases is reported for extrahepatic tissues including lung, kidney, gastrointestinal tract, endothelium and heart (Thum \& Borlak 2000a). Heart tissue is metabolically competent and disease may 

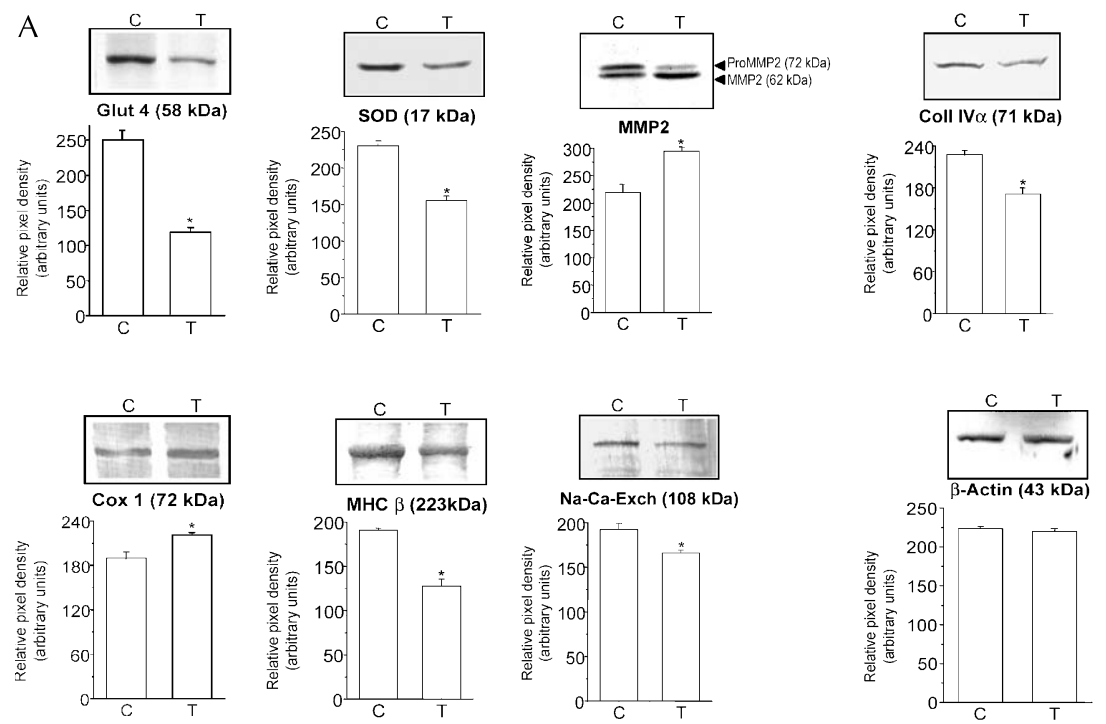

B

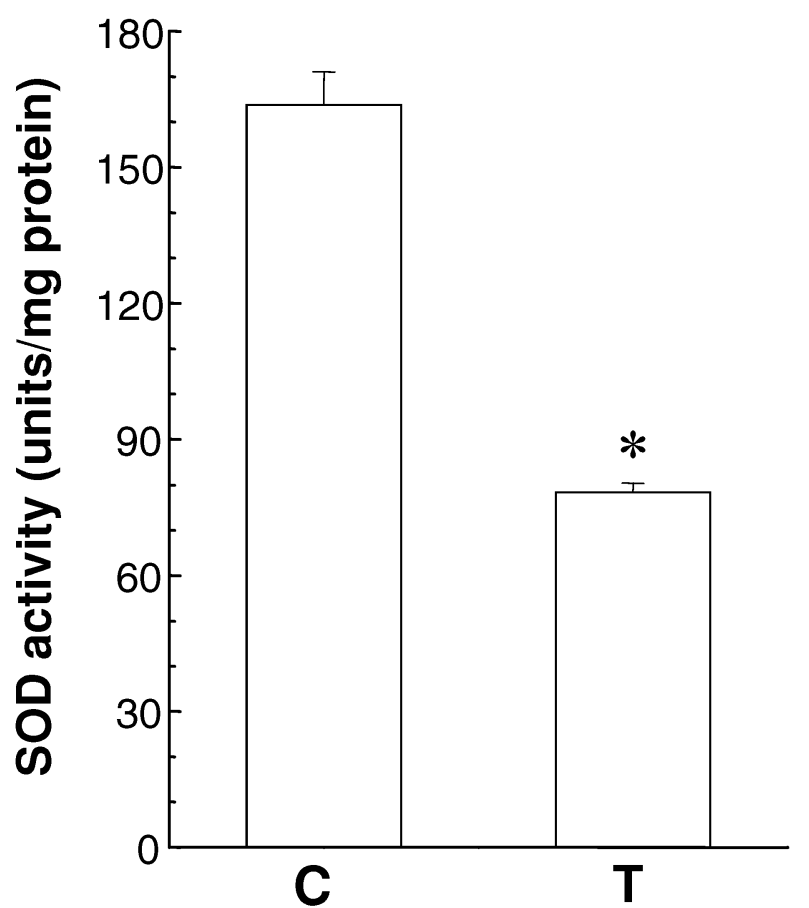

Figure 3 Validation of microarray results. (A) Representative immunoblots showing alteration of proteins in ventricular tissues obtained from rat treated with vehicle $(C)$ or T3 (T) for 15 days. The approximate molecular masses of the proteins are given in parentheses. The levels of the proteins were quantitated using the software Image $(\mathrm{NIH}$, USA) and the pixel intensities are shown as histograms. Immunoblots with $\beta$-actin antibody confirmed the equal amount of protein loading of the whole homogenate and microsome preparations (Fig. 6B). Each immunoblot was repeated with the samples from three different hearts $(n=3)$. ${ }^{*} P<0.05$ vs control. (B) Activity of $\mathrm{Cu}, \mathrm{Zn}$-SOD in the heart tissues obtained from control $(\mathrm{C})$ and T3-treated $(\mathrm{T})$ rats. The results are means \pm S.E.M. of three individual rats. ${ }^{*} P<0 \cdot 01$ vs control. 


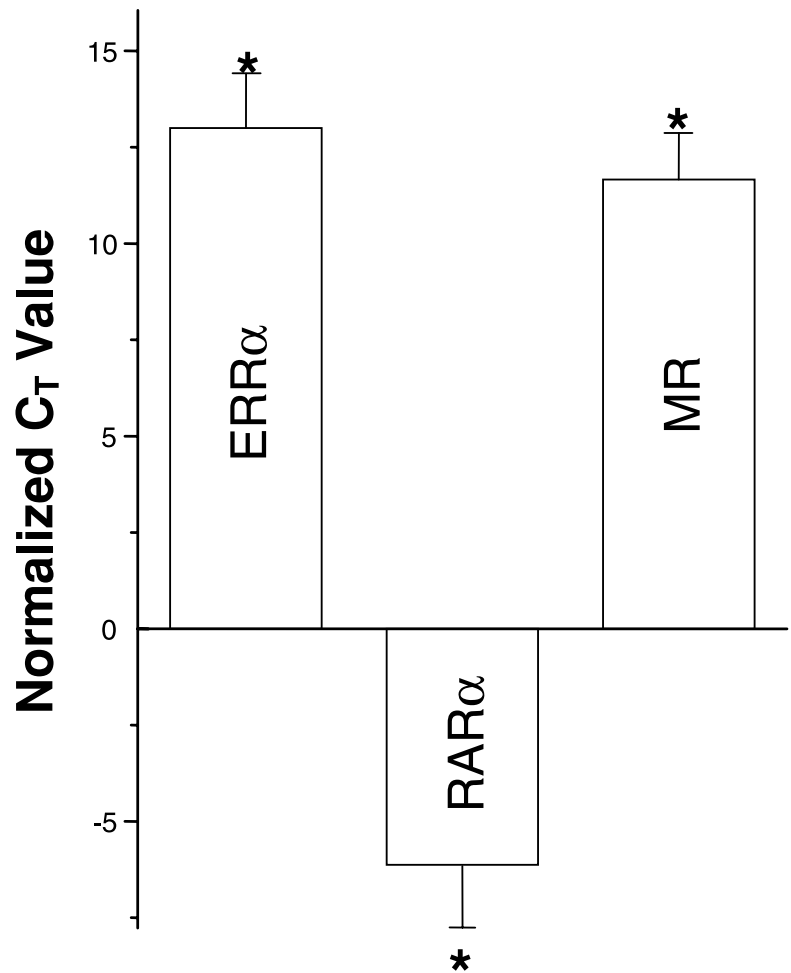

Figure 4 Validation of microarray results by real-time quantitative RT-PCR analysis. Expression patterns of ERR $\alpha, R A R \alpha$ and MR were examined by real-time quantitative RT-PCR analysis using RNA samples prepared from left ventricular tissues of rat treated with vehicle (control) or T3 for 15 days. Each bar represents the percentage change in $C_{\mathrm{T}}$ value over the control after normalization with the $C_{T}$ value of GAPDH mRNA as described in Materials and Methods. Each experiment was repeated with three different batches of samples. ${ }^{*} P<0 \cdot 05$ vs control.

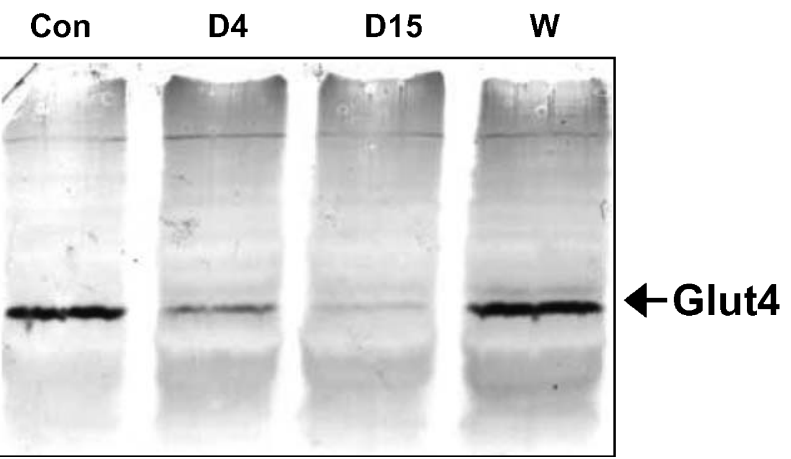

Figure 5 Effect of T3 on GLUT4 expression in ventricular tissues. Representative immunoblots showing GLUT4 expression in the ventricular microsome preparations obtained from rats treated without (Con) or with T3 for 4 days (D4) and 15 days (D15) or treated for 15 days and then left for 15 days without treatment (W).

influence the expression of cytochrome P450 monooxygenases (Thum \& Borlak 2000b). In the hypertrophied heart of spontaneously hypertensive rat, the expression and activities of cytochrome P450 mono-oxygenases were shown to be induced resulting in increased lipid peroxidation and oxidative stress (Thum \& Borlak 2002). In agreement with these results, we also show a dramatic increase in the expression of cytochrome P450 isoforms in the left ventricular tissues of hyperthyroid rat. This is likely to be due to a direct effect of T3 on cardiac metabolism. Furthermore an increased amount of lipid peroxidation (data not shown) and a decreased level and activity of SOD1 (Table 1, Figs 3A and B), in thyroid hormoneinduced rat heart indicates the occurrence of severe oxidative stress. Such a decrease in the level and activity of SOD due to increased oxidative stress has also been reported by others in a number of different experimental situations (Indik et al. 2001, Simon-Giavarotti et al. 2002).

Thyroid hormone-induced hypermetabolism, involving all major fuel sources, is a hallmark of hyperthyroidism (Moller et al. 1996). As a direct consequence of hypermetabolism, T3 also alters a series of enzymes of the metabolic pathway in the heart such as high-density lipoproteinbinding proteins, adipocyte fatty acid binding protein, phospholipid transporter, COX1 and glucose transporter (Table 1). The lowering of plasma lipid levels by $\mathrm{T}_{3}$ (Trost et al. 2000) could be linked to the reduced expression of fatty acid and lipid targeting proteins such as adipocyte fatty acid binding protein and phospholipid transporters respectively. Excess of thyroid hormone affects intermediary metabolism (Moller et al. 1996) and as a result, COX1 might have increased in the heart of hyperthyroid rat.

Consistent with earlier reports, microarray analysis reveals the differential expression of $\mathrm{MHC}$ genes, i.e. upregulation of MHC- $\alpha$ and repression of MHC- $\beta$ in the heart of hyperthyroid rat (Table 1, Fig. 3A). Cardiac tissues that contain relatively more MHC- $\alpha$ than MHC- $\beta$ contract faster than those in which the ratio of MHC- $\alpha$ to MHC- $\beta$ is low. This could explain the increased heart rate in the hyperthyroid condition.

It is interesting to observe that MMP2 is increased as revealed by microarray and Western blot analyses whereas TIMP2 expression is decreased (Table 1). We examined the expression of TIMP2, the endogenous inhibitor of MMP2, by semi-quantitative RT-PCR. Concomitant with the increased expression of MMP2 by microarray and immunoblotting, the expression of TIMP2 was decreased. Consistent with these effects, expressions of collagen IV $\alpha 4$ and collagen XVI $\alpha 1$ are decreased in the heart of hyperthyroid rat. A possible mechanism involves reduction of collagen synthesis coupled with increased MMP2 activity leading to the low collagen deposition in the heart of hyperthyroid rat.

The present study shows that phospholamban is downregulated in the hyperthyroid heart as reported earlier (Kiss et al. 1994). Downregulation of phospholamban expression has further strengthened our microarray analysis since the regulation of phospholamban in relation to pathophysiology of the hyperthryroid heart is well established (Kiss et al. 


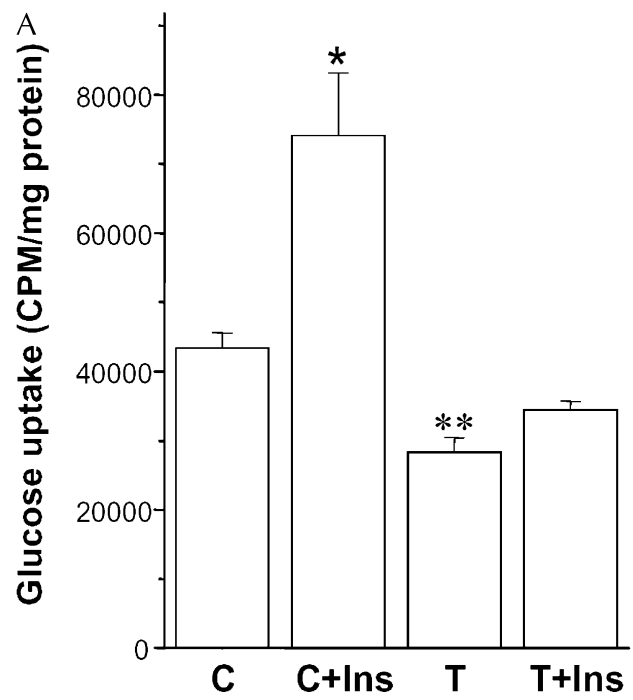

B

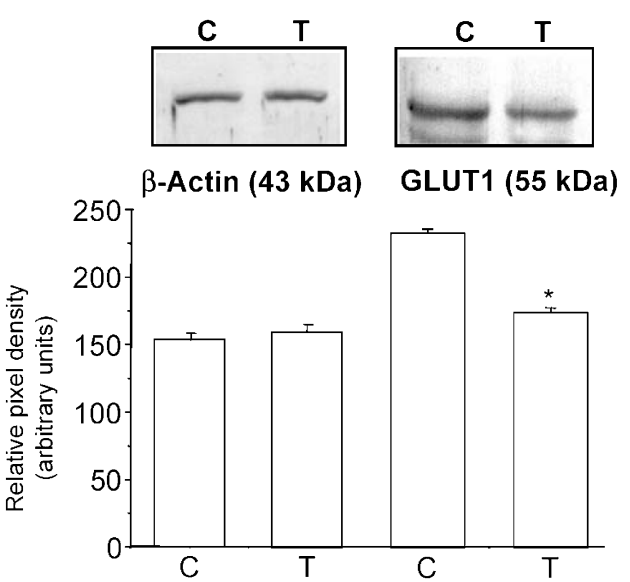

Figure 6 Effect of T3 on glucose transport into adult rat ventricular cardiomyocytes. (A) Cardiomyocytes were prepared from the adult rat heart injected with vehicle (C) or T3 (T) for 15 days. The cells prepared from vehicle or T3-treated rats were stimulated without (C) or with $100 \mathrm{nM}$ insulin (Ins) for 30 min followed by incubation for $5 \mathrm{~min}$ in the presence of 2-deoxy-D- $\left[{ }^{3} \mathrm{H}\right]$-glucose $(0.4 \mathrm{nmol})$ as described in Materials and Methods. $\left[{ }^{3} \mathrm{H}\right]$ deoxy glucose was measured in a liquid scintillation counter and results are expressed as c.p.m. per mg protein. Each bar represents the mean \pm S.E.M. of three individual animals, each in duplicate. ${ }^{*} P<0.01$ vs control; ${ }^{* *} P<0.05$ vs control. (B) The expression level of GLUT1 in the ventricular tissues of hyperthyroid rat heart is significantly $(P<0 \cdot 05, n=3)$ reduced as detected by Western blot analysis. Equal amounts of protein $(50 \mu \mathrm{g})$ of microsome preparations were used for immunoblotting with the $\beta$-actin antibody as loading control.

1998, Holt et al. 1999). However, SERCA is not depicted in the present study since the microarray blot does not include this cDNA. In the cardiac myocytes, $\mathrm{Ca}^{2+}$ release and reuptake by the sarcoplasmic reticulum regulate the rate of myocardial fiber contraction and relaxation. Phospholamban phosphorylates SERCA and inhibits its ability to reuptake $\mathrm{Ca}^{2+}$ into the lumen of sarcoplasmic reticulum. It is known that thyroid hormone allows an accelerated reuptake of calcium by the sarcoplasmic reticulum by upregulation of SERCA and downregulation of phospholamban protein expression (Fadel et al. 2000). This is a mechanism by which thyroid hormone improves the diastolic relaxation properties of the hyperthyroid heart.

Hyperthyroid rat heart shows an altered level of expression of some of the nuclear hormone receptors such as ERR $\alpha, \operatorname{RAR} \alpha, \operatorname{RAR} \gamma$, mineralocorticoid receptors etc. Retinoid receptors such as specific RARs and retinoic acid $\mathrm{X}$ receptors (RXRs) hetero- or homodimerize with specific regulatory sequences in gene promoters (Leng et al. 1994). Retinoids have long been recognized as important for cardiac morphogenesis and differentiation (Colbert et al. 1997). The present study shows for the first time that thyroid hormone mediated cardiac hypertrophy is signalled through the retinoid signaling pathway specifically via upregulation of RAR $\alpha$ (Table 1 , Fig. 4). It is likely that hyperthyroid rat heart requires upregulation of its transactivators RARs and thus $\mathrm{RAR} \alpha$ expression is increased by more than $26 \%$ of its normal level. Microarray analysis show an altered expression of other nuclear hormone receptors as mentioned in Table 1, however the physiological significance of such alterations requires further study.

To meet energy demands for contractile function or increased workload, the heart utilizes a variety of substances including glucose, fatty acids, lactate, ketone bodies and amino acids. The rate of glucose utilization in the heart is greater than in many other tissues such as skeletal muscle, adipose tissues or lung (James et al. 1985a,b, Zorzano et al. 1997). Thus, glucose transport/ utilization is critical for the maintenance of normal function. Glucose uptake in the heart is mediated by the facilitative transporter GLUT4 and to a lesser extent by GLUT1 (Young et al. 1997). Insulin stimulates GLUT4 translocation in the heart from the intracellular storage membrane to the cell surface where they facilitate glucose entry into the cell (Sun et al. 1994, Young et al. 1997). Surprisingly, microarray, and Northern and Western blot analyses show a reduction of GLUT4 expression in the T3-treated left ventricular tissues in a situation when cardiomyocytes require more energy under increased workload. Initially, the expression of GLUT4 is reduced a little which was considerably declined after 15 days of T3 treatment suggesting that GLUT4 expression is affected due to the prolonged hyperthyroid condition (Fig. 5). A 
recent report shows that reduction of GLUT4 results in the development of cardiac hypertrophy in mice (Kaczmarczyk et al. 2003). The cardiac myocytes prepared from adult rat treated with T3 show a decreased glucose uptake in response to insulin compared with the untreated cardiomyocytes (Fig. 6). Depolarization across the plasma membrane results in $\mathrm{Ca}^{2+}$-induced $\mathrm{Ca}^{2+}$ release, which is directly linked to excitation-contraction coupling of myofibrils (Hoffmann et al. 1995). It is known that $\mathrm{KCl}$ induces depolarization of cardiac myocytes in vitro and this process stimulates glucose entry into the myocytes. It is interesting that $\mathrm{KCl}$-induced glucose uptake was also inhibited in cardiomyocytes of T3-treated rat heart compared with the untreated control (data not shown).

Taken together, we demonstrate the gene expression profile in left ventricular tissues of hyperthyroid rat in which some of the altered genes are common to pathological hypertrophy. Alteration of GLUT4 expression is one of the distinct features of hyperthyroid-induced altered gene expression leading to impaired glucose transport into the myocytes which could be detrimental to cardiac physiology if prolonged hyperthyroidism is unchecked.

\section{Acknowledgements}

The authors are thankful to Dr Jeffry E Pessin, University of Iowa for providing GLUT4 cDNA and to Dr Do Han Kim (Gwangju Institute of Science and Technology, South Korea) for kindly donating MHC antibody.

\section{Funding}

This work is supported by grants to the Indian Institute of Chemical Biology by the Council of Scientific and Industrial Research, New Delhi and Department of Science and Technology (SP/SO/B50/2001). There is no conflict of interest that would prejudice the impartiality of the research.

\section{References}

Bandyopadhyay A, Shin DW, Ahn JH \& Kim DH 2000 Calcineurin regulates ryanodine receptor/Ca release channels in rat heart. Biochemical Journal 352 61-70.

Bing OH, Hague NL, Perreault CL, Conrad CH, Brooks WW, Sen S \& Morgan JP 1994 Thyroid hormone effects on intracellular calcium and inotropic responses of rat ventricular myocardium. American Journal of Physiology 267 H1112-H1121.

Chien KR, Zhu H, Knowlton KU, Miller HW, Van BM, O'Brien TX \& Emans SM 1993 Transcriptional regulation during cardiac growth and development. Annual Review of Physiology 55 77-95.

Cohn JN 1996 The management of chronic heart failure. New England Journal of Medicine 335 490-498.
Colbert MC, Hall DG, Kimball TR, Witt SA, Lorenz JN, Kirby ML, Hewett TE, Klevitsky R \& Robbins J 1997 Cardiac

compartment-specific overexpression of a modified retinoic acid receptor produces dilated cardiomyopathy and congestive heart failure in transgenic mice. Journal of Clinical Investigation $\mathbf{1 0 0}$ 1958-1968

Degens H, Gilde AJ, Lindhout M, Willemsen PH, Van Der Vusse GJ \& Van Bilsen M 2003 Functional and metabolic adaptation of the heart to prolonged thyroid hormone treatment. American Journal of Physiology-Heart and Circulatory Physiology 284 H108-H115.

Dillmann WH 1990 Biochemical basis of thyroid hormone action in the heart. American Journal of Medicine 88 626-630.

Fadel BM, Ellahham S, Ringel MD, Lindsay J, Wartofsky L \& Burman KD 2000 Hyperthyroid heart disease. Clinical Cardiology 23 402-408.

Feldman AM, Weinberg EO, Ray PE \& Lorell BH 1993 Selective changes in cardiac gene expression during compensated hypertrophy and the transition to cardiac decompensation in rats with chronic aortic banding. Circulation Research 73 184-192.

Feng X, Jiang Y, Meltzer P \& Yen PM 2000 Thyroid hormone regulation of hepatic genes in vivo detected by complimentary DNA microarray Molecular Endocrinology 14 947-955.

Gay RG, Graham S, Aguirre M, Goldman S \& Morkin E 1988 Effects of 10- to 12-day treatment with L-thyroxine in rats with myocardial infarction. American Journal of Physiology 255 H801-H806.

Hamasaki Y, Shinohara O, Ishida H, Hayashi Y \& Nakazawa H 2000 Decreased protein kinase $\mathrm{C}$-epsilon expression in hyperthyroid cardiac ventricles induced by triiodothyronine treatment in the rat. Life Sciences 67 1859-1869.

Hoffmann P, Richards D, Heinroth-Hoffmann I, Mathias P, Wey H \& Toraason M 1995 Arachidonic acid disrupts calcium dynamics in neonatal rat cardiac myocytes. Cardiovascular Research 30 889-898.

Holt E, Sjaastad I, Lunde PK, Christensen G \& Sejersted OM 1999 Thyroid hormone control of contraction and the $\mathrm{Ca}(2+)-\mathrm{ATPase} / \mathrm{phospholamban}$ complex in adult rat ventricular myocytes. Journal of Molecular and Cellular Cardiology 31 645-656.

Indik JH, Goldman S \& Gaballa MA 2001 Oxidative stress contributes to vascular endothelial dysfunction in heart failure. American Journal of Physiology, Heart and Circulatory Physiology 281 H1767-H1770.

Izumo S, Lompre AM, Matsuoka R, Koren G, Schwartz K, Nadal-Ginard B \& Mahdavi V 1987 Myosin heavy chain messenger RNA and protein isoform transitions during cardiac hypertrophy. Interaction between hemodynamic and thyroid hormone-induced signals. Journal of Clinical Investigation 79 970-977.

James DE, Jenkins AB \& Kraegen EW 1985a Heterogeneity of insulin action in individual muscles in vivo: euglycemic clamp studies in rats. American Journal of Physiology 248 E567-E574.

James DE, Kraegen EW \& Chisholm DJ 1985 b Muscle glucose metabolism in exercising rats: comparison with insulin stimulation. American Journal of Physiology 248 E575-E580.

Kaczmarczyk SJ, Andrikopoulos S, Favaloro J, Domenighetti AA, Dunn A, Ernst M, Grail D, Fodero-Tavoletti M, Huggins CE, Delbridge LM et al. 2003 Threshold effects of glucose transporter-4 (GLUT4) deficiency on cardiac glucose uptake and development of hypertrophy. Journal of Molecular Endocrinology 31 449-459.

Kinugawa K, Yonekura K, Ribeiro RC, Eto Y, Aoyagi T, Baxter JD, Camacho SA, Bristow MR, Long CS \& Simpson PC 2001 Regulation of thyroid hormone receptor isoforms in physiological and pathological cardiac hypertrophy. Circulation Research $\mathbf{8 9}$ 591-598.

Kiss E, Brittsan AG, Edes I, Grupp IL, Grupp G \& Kranias EG 1998 Thyroid hormone-induced alterations in phospholamban-deficient mouse hearts. Circulation Research 21 608-613.

Kiss E, Jakab G, Kranias EG \& Edes I 1994 Thyroid hormone-induced alterations in phospholamban protein expression: regulatory effects on sarcoplasmic reticulum $\mathrm{Ca}^{2+}$ transport and myocardial relaxation. Circulation Research 75 245-251. 
Klein I \& Ojamaa K 2001 Thyroid hormone and the cardiovascular system. New England Journal of Medicine 344 501-509.

Leng X, Blanco J, Tsai SY, Ozato K, O’Mally BW \& Tsai MJ 1994 Mechanisms for synergistic activation of thyroid hormone receptor and retinoid $\mathrm{X}$ receptor on different response elements. Journal of Biological Chemistry 269 31436-31442.

MacKinnon R, Gwathmey JK, Allen PD, Briggs GM \& Morgan JP 1988 Modulation by the thyroid state of intracellular calcium and contractility in ferret ventricular muscle. Circulation Research $\mathbf{6 3}$ 1080-1089.

Mahaffey KW, Raya TE, Pennock GD, Morkin E \& Goldman S 1995 Left ventricular performance and remodeling in rabbits after myocardial infarction. Effects of a thyroid hormone analogue. Circulation 91 794-801.

Martin JP, Dailey M \& Sugarman E 1987 Negative and positive assays of superoxide dismutase based on hematoxylin autooxidation. Archives of Biochemistry and Biophysics 255 329-336.

Moller N, Nielson S, Nyholm B, Porksen N, Alberti KG \& Weeke J 1996 Glucose turnover, fuel oxidation and forearm substrate exchange in patients with thyrotoxicosis before and after medical treatment. Clinical Endocrinology 44 453-459.

Ojamaa K, Klien I, Sabet A \& Steinberg SF 2000 Changes in adenylyl cyclase isoforms as a mechanism for thyroid hormone modulation of cardiac $\beta$ adrenergic receptor responsiveness. Metabolism 49 275-279.

Oppenheimer JA, Schwatz HL, Mariash CN, Kinlaw WB, Wong NCW \& Freake HC 1987 Advances in our understanding of thyroid hormone action at the cellular level. Endocrine Reviews $\mathbf{8}$ 288-308.

Pennock GD, Raya TE, Bahl JJ, Goldman S \& Morkin E 1993 Combination treatment with captopril and the thyroid hormone analogue 3,5-diiodothyropropionic acid: a new approach to improving left ventricular performance in heart failure. Circulation 88 1289-1298.

Piper HM, Probst I, Schwartz P, Hutter JF \& Spieckermann PG 1982 Culturing of calcium stable adult cardiomyocytes. Journal of Molecular and Cellular Cardiology 14 397-412.

Roy SS, Mukherjee M, Bhattacharya S, Mandal CN, Kumar LR, Dasgupta S, Bandyopadhyay I \& Wakabayashi KA 2003 New cell secreting insulin. Endocrinology 144 1585-1593.

Schaible TF, Ciambrone GJ, Capasso JM \& Scheuer J 1984 Cardiac conditioning ameliorates cardiac dysfunction associated with renal hypertension in rats. Journal of Clinical Investigation 73 1086-1094.

Scheuer J \& Battrick PM 1987 The cardiac hypertrophic responses to pathologic and physiologic loads. Circulation 75 163-168.
Simon-Giavarotti KA, Giavarotti L, Gomes LF, Lima AF, Veridiano AM, Garcia EA, Mora OA, Fernandez V, Videla LA \& Junqueira VB 2002 Enhancement of lindane-induced liver oxidative stress and hepatotoxicity by thyroid hormone is reduced by gadolinium chloride. Free Radical Research 36 1033-1039.

Sun D, Nguyen N, DeGrado TR, Schwaiger M \& Brosius FC 1994 Ischemia induces translocation of the insulin-responsive glucose transporter GLUT4 to the plasma membrane of cardiac myocytes. Circulation 89 793-798.

Thum T \& Borlak J 2000a Cytochrome P450 mono-oxygenase gene expression and protein activity in cultures of adult cardiomyocytes of the rat. British Journal of Pharmacology 130 1745-1752.

Thum T \& Borlak J 20006 Gene expression in distinct regions of the heart. Lancet 18 979-983.

Thum T \& Borlak J 2002 Testosterone, cytochrome P450, and cardiac hypertrophy. FASEB Journal 16 1537-1549.

Trost SU, Swanson E, Gloss B, Wang-Iverson DB, Zhang H, Volodarsky T, Grover GJ, Baxter JD, Cheillini G, Scanlan TS et al. 2000 The thyroid hormone receptor- $\beta$-selective agonist GC-1 differentially affects plasma lipids and cardiac hypertrophy. Endocrinology 141 3057-3064.

Weitzel JM, Radtke C \& Seitz HJ 2001 Two thyroid hormone-mediated gene expression patterns in vivo identified by cDNA expression arrays in rat. Nucleic Acid Research 29 5148-5155.

Weitzel JM, Hamann S, Jauk M, Lacey M, Filbry A, Radtke C, Iwen KA, Kutz S, Harneit A, Lizardi PM et al. 2003 Hepatic gene expression patterns in thyroid hormone-treated hypothyroid rats. Journal of Molecular Endocrinology 31 291-303.

Young LH, Renfu Y, Russell R, Hu X, Caplan M, Ren J, Shulman GI \& Sinusas AJ 1997 Low flow ischemia induces translocation of canine heart Glut 4 and Glut 1 glucose transporters to sarcolemma in vivo. Circulation 95 415-422.

Zorzano A, Sevilla L, Camps M, Becker C, Meyer J, Kammermeier H, Munoz P, Guma A, Testar X, Palacin M et al. 1997 Regulation of glucose transport, and glucose transporters expression and trafficking in the heart: studies in cardiac myocytes. American Journal of Cardiology 80 65A-76A.

Received 20 May 2004

Accepted 1 June 2004

Made available online as an

Accepted Preprint 8 June 2004 